\title{
Use of both Smoked and Non-smoked Tobacco Products
}

National Cancer Institute

\section{Source}

National Cancer Institute. Use of both Smoked and Non-smoked Tobacco Products. NCI

Thesaurus. Code C154515.

An indication that individual only used both smoked and smokeless tobacco products. 